\title{
HISTÓRIAS DE VIDA NA PERSPECTIVA DA PROFISSÃO DOCENTE E DA GESTÃO EM SALA DE AULA
}

http://dx.doi.org/10.5902/2318133831003

\author{
Severino Roberto de Lima \\ Secretaria da Educação do Estado do Tocantins, Brasil.
}

\begin{abstract}
Resumo
Neste artigo apresentam-se resultados referentes à pesquisa sobre a história de vida de professores que lecionam matemática: sua infância enquanto aluno, suas relações e concepções com a matemática e a escolha da profissão docente. Trata-se de uma pesquisa bibliográfica e de campo com professores do Ensino Fundamental II do Colégio Estadual Criança Esperança, localizado em Palmas, Estado do Tocantins. Realizamos entrevistas semiestruturadas com três professoras utilizando a metodologia da História Oral. Os resultados mostram que essas professoras, nascidas no interior, estudaram em escolas públicas, já possuíam alguma relação de proximidade desde a infância com a disciplina, demonstravam habilidades cognitivas e raciocínio lógico e que, possivelmente, esse fator tenha influenciado na escolha da profissão.

Palavras-chave: educação matemática; profissão docente; gestão.
\end{abstract}

\section{LIFE STORIES IN THE PERSPECTIVE OF TEACHING PROFESSION AND MANAGEMENT IN AULA ROOM}

\begin{abstract}
This article presents results concerning the life history research of teachers who teach mathematics: their childhood as a student, their relationships and conceptions with mathematics and the choice of the teaching profession. This is a bibliographical and field research with teachers of Elementary School II - Child Hope State College - Palmas Tocantins. We conducted semistructured interviews with three teachers using Oral History methodology as the medium. The results show that these teachers were born in the interior, studied in public schools, had some relationship of proximity from childhood with the discipline, demonstrated cognitive abilities and logical reasoning, possibly this factor influenced the choice of profession.

Key-words: mathematics education; occupation teacher; management.
\end{abstract}




\section{Introdução}

preocupação com o professor, o ensino e aprendizagem da Matemática, tão
fortemente ligadas ao presente e às projeções para o futuro, tão cuidadoso
daquilo que realmente interessaria ensinar e aprender, de modo que a Matemática faça sentido hoje e amanhã aos alunos, têm descuidado da dimensão histórica. Esse descuido, não raro, faz subtrair à análise e às propostas de transformação as heranças que todos os ofícios carregam consigo. Sem ter presente essa dimensão histórica, os projetos de melhoria do ensino em educação matemática tendem ao fracasso. O ofício de ser professor de Matemática, como a maioria das profissões, é herdeiro de práticas e saberes que vêm de diferentes épocas. Amalgamados, reelaborados, descartados, transformados, eles constituem a herança através da qual é possível a produção de novos saberes e a criação de novas práticas presentes no cenário pedagógico atual. Afinal de contas, ensinamos aos nossos alunos o que aprendemos e construímos ao longo da profissão docente.

Nesse sentido, os alunos questionam sobre a necessidade de aprender determinado conteúdo e nem sempre é possível uma resposta honesta para esses questionamentos. A insatisfação por parte dos alunos revela que existem problemas a serem enfrentados, tais como a necessidade de rever a prática associada aos saberes docentes, até então, centrados nos moldes do ensino tradicional. De acordo com Micotti (1999) as aulas consistem, sobretudo, em explanações sobre temas do programa; entende-se que basta o professor dominar a matemática que leciona para ensinar bem.

$\mathrm{Na}$ busca de respostas para essas questões e de novas alternativas que facilitem essa prática, procuram-se atualizar da maneira que se pode. Comprando livros, participando de palestras, formações continuadas oferecidas pela escola onde trabalha e pela Secretaria Estadual da Educação, enfim, participam de todos os cursos e eventos que surgem. Mas ainda é pouco, porque a "atualização acadêmica adquirida, nem chega perto da "realidade" dos alunos e os questionamentos continuam" (Grifo meu).

Nessa busca contínua por mudanças, uma nova solução parecia se delinear: a chave era dar significado ao ensino da Matemática, ou seja, apresentar aos alunos uma Matemática dinâmica, de hoje, em movimento e que esteja em constante evolução assim, como as tecnologias. Ferreira (2003), afirma que até meados da década de 1980 pouco se havia escrito e pesquisado sobre a formação de professores e menos ainda sobre a formação de professores de matemática, no Brasil. Entretanto, a partir dos últimos anos dessa década, esse tema começa a delinear-se consistentemente e a tornar-se uma das mais ativas áreas de pesquisa em educação.

Assim sendo, a história da educação matemática começa criar novos marcos de referências, novas formas e perspectivas de perceber e reagir. A criação e construção de uma realidade obrigam o professor a ir além das regras, fatos, teorias e procedimentos conhecidos e disponíveis. Segundo Tardif (2012) o saber não é uma substância ou um conteúdo fechado em si mesmo; ele se manifesta através de relações complexas entre o professor e seus alunos. Nesse contexto, a Matemática torna-se componente importantíssima na construção do conhecimento, e nas distintas maneiras de fazer e de saber comparar, classificar, quantificar, e de algum modo, avaliar, considerando o contexto em que a sociedade se utiliza, cada vez mais, de conhecimentos científicos e de recursos tecnológicos. 


\section{A matemática no ensino fundamental e a profissão docente}

$O$ interesse pela história oral ganha fôlego no mundo atual por estarmos nos questionando sobre a própria concepção de História, quando parece haver um interesse generalizado nos processos que envolvem as memórias individuais e coletivas, num momento em que segundo Santamarina e Marinas (1995), precisamente a sociedade dos meios de massificação pretende homogeneizar todas as formas de saber e de comunicação social. As Histórias de vida ou, com uma possível liberdade: os relatos orais como dados históricos, estão fortemente vinculados e, na verdade, surgem com a Antropologia.

Em seu início, o recurso das histórias de vida é orientado pela prática antropológica, visando por em circulação, numa sociedade que vai se industrializando, no início do século, outras formas de vida além daquelas até então presentes nos estudos.

A Matemática comporta um amplo campo de relações, regularidades e coerências que despertam a curiosidade e instigam a capacidade de generalizar, projetar, prever e abstrair, favorecendo a estruturação do pensamento e o desenvolvimento do raciocínio lógico. Faz parte da vida de todas as pessoas nas experiências mais simples como contar, comparar e operar sobre quantidades. Nos cálculos relativos a salários, pagamentos e consumo, na organização de atividades como agricultura e pesca, a Matemática se apresenta como um conhecimento de muita aplicabilidade. Também é um instrumental importante para diferentes áreas do conhecimento, por ser utilizada em estudos ligados às ciências da natureza como às ciências sociais e por estar na composição musical, na coreografia, na arte e nos esportes.

\section{Dificuldades na aprendizagem da Matemática}

Atualmente o tema dificuldade na aprendizagem no ensino da Matemática tem sido objeto de pesquisas, palestras, encontros, fóruns, com o objetivo de discutir e descobrir as origens de tantos problemas no ensino dessa disciplina. Algumas questões são recorrentes nestes debates e pesquisas, tais como: A deficiência está no próprio sistema de ensino? Os professores não estão conseguindo lidar com o processo? Os alunos não estariam desmotivados? O que leva o aluno a não conseguir aprender Matemática e/ou outras disciplinas? Além dessas dificuldades pontuadas, evidentemente, muitas outras questões vêm sendo levantadas a fim de buscar uma resposta e possíveis soluções para os problemas enfrentados atualmente na gestão da sala de aula.

Entende-se que o primeiro passo para discutir essas questões é a compreensão do que venha a ser considerado como dificuldades de aprendizagem no processo do ensino da matemática. Para tanto, é necessário um trabalho de investigação que possa elencar essas dificuldades e busque conhecer se 0 aluno com dificuldades de aprendizagem possui ou não sintomas diferenciados no modo de processar os dados numéricos, ou se 0 processamento é semelhante ao de outros alunos, os quais conseguem processar dados com mais agilidade fazendo uso do raciocínio lógico. Sanchez (2004) destaca que as dificuldades de aprendizagem em Matemática podem se manifestar nos seguintes aspectos: 
Nas dificuldades quanto às crenças, às atitudes, às expectativas e aos fatores emocionais acerca da matemática. São questões de grande interesse, com o tempo podem dar lugar ao fenômeno da ansiedade para com a matemática sintetizando o acúmulo de problemas que os alunos maiores experimentam diante do contato com a matemática. (p. 174).

Ressalta-se que não existe uma causa única que justifique as bases das dificuldades com a linguagem Matemática, que podem ocorrer por falta de aptidão para a razão matemática ou pela dificuldade em elaboração do cálculo. Essa dificuldade não se relaciona com a ausência das habilidades básicas de contagem, mas sim com a capacidade de relacioná-las com o mundo. A capacidade que o aluno adquire de explicar, de aprender e compreender situações, constituem segundo D`Ambrósio (2005), a aprendizagem por excelência. Assim sendo, cada indivíduo organiza seu processo intelectual ao longo de sua história de vida.

\section{O professor de Matemática e os saberes}

A preocupação com o professor, sua formação e a gestão em sala de aula vem ganhando lugar de destaque nas atuais discussões sobre a educação escolar. Inquietações e debates sobre esse tema justificam-se na medida em que o professor é considerado como o principal mediador entre a escola e os alunos e, nesse sentido, acaba sendo alvo de críticas quando se discutem questões relativas à aprendizagem dos alunos.

$\mathrm{Na}$ vida profissional o professor de Matemática defronta-se com múltiplas situações para as quais não encontra respostas pré-estabelecidas e que não são suscetíveis de serem analisadas pelo processo clássico de investigação científica. Na prática, os professores possivelmente não busquem compartilhar esses problemas com seus pares, ou talvez não utilizem os saberes adquiridos ao longo da profissão docente, considerando que a interação do indivíduo com a realidade e com outros agentes, poderá ser um agente de transformação para o desenvolvimento cognitivo e da profissão. Portanto, os saberes tornam-se componentes indispensáveis para o equilíbrio da prática e da gestão em sala de aula. Logo a seguir, mostraremos um quadro colocando em evidência as fontes de aquisição desses saberes e seus modos de integração no trabalho docente.

Quadro 1-

Os saberes dos professores.

\begin{tabular}{|c|c|c|}
\hline Saberes dos professores & Fontes sociais de aquisição & $\begin{array}{c}\text { Modos de integração no } \\
\text { trabalho docente }\end{array}$ \\
\hline $\begin{array}{l}\text { Saberes pessoais dos } \\
\text { professores }\end{array}$ & $\begin{array}{l}\text { ida, a } \\
\text { etc. }\end{array}$ & $\begin{array}{l}\text { Pela história de vida e pela } \\
\text { socialização primária }\end{array}$ \\
\hline $\begin{array}{l}\text { Saberes provenientes da } \\
\text { formação escolar anterior }\end{array}$ & $\begin{array}{l}\text { dária, } \\
\text { dários }\end{array}$ & $\begin{array}{l}\text { Pela formação e e pela } \\
\text { socialização pré-profissionais }\end{array}$ \\
\hline $\begin{array}{l}\text { Saberes provenientes da } \\
\text { formação profissional para } \\
\text { o magistério }\end{array}$ & $\begin{array}{lll}\text { Os estabelecimentos } & \text { de } \\
\text { formação de professores, os } \\
\text { estágios, os cursos } & \text { de } \\
\text { reciclagem, etc. } & & \end{array}$ & $\begin{array}{llr}\text { Pela formação e pela } & \text { e } \\
\text { socialização profissional } & \text { nas } \\
\text { instituições de formação } & \text { de } \\
\text { professores } & & \end{array}$ \\
\hline $\begin{array}{lcr}\text { Saberes provenientes dos } & \text { pros } \\
\text { programas } & \text { e } & \text { livros } \\
\text { didáticos } & \text { usados } & \text { no } \\
\text { trabalho } & & \\
\end{array}$ & $\begin{array}{l}\text { A utilização das ferramentas } \\
\text { dos professores: programas, } \\
\text { livros didáticos, cadernos de } \\
\text { exercício, fichas, etc. }\end{array}$ & $\begin{array}{l}\text { Pela utilização das ferramentas } \\
\text { de trabalho, sua adaptação às } \\
\text { tarefas }\end{array}$ \\
\hline
\end{tabular}




\begin{tabular}{|l|l|l|}
\hline $\begin{array}{l}\text { Saberes provenientes de } \\
\text { sua própria experiência na } \\
\text { profissão, na gestão da } \\
\text { sala de aula e na escola }\end{array}$ & $\begin{array}{l}\text { A práca do ofício na escola e } \\
\text { na sala de aula, a experiência } \\
\text { dos pares, etc. }\end{array}$ & $\begin{array}{l}\text { Pela prática do trabalho, pela } \\
\text { gestão e e socialização } \\
\text { profissional. }\end{array}$ \\
\hline
\end{tabular}

Fonte: Tardif, 2012, p. 63.

Este quadro põe em evidência vários fenômenos importantes. Em primeiro lugar, de acordo com Tardif (2012), todos os saberes nele identificados são realmente utilizados pelos professores no contexto de sua profissão e na gestão da sala de aula.

Assim, optou-se por realizar uma pesquisa bibliográfica sobre a história de vida de professores de Matemática do ensino fundamental. Depois a pesquisa de campo, realizada no município de Palmas, Tocantins, especificamente no Colégio Estadual Criança Esperança, onde foram entrevistadas três professoras de Matemática. O estudo teve como foco o período da infância e as aptidões, suas relações com a matemática enquanto aluno, a escolha da profissão, as dificuldades encontradas, as aprendizagem dos alunos e a gestão da sala de aula.

\section{Resultados}

Após os dados coletados pelas entrevistas realizadas com três professoras que lecionam a disciplina de Matemática nos anos finais do ensino fundamental no Colégio Estadual Criança Esperança, nos possibilitou uma análise em relação à história de vida dessas professoras Maria Evanete, Maria Tereza e Cristina de Souza.

Em conversa com a professora Evanete, em relação ao seu período da infância, se existiu ou não alguma relação com a matemática, à professora faz o seguinte relato:

Eu nasci no interior do interior do Piauí, fazenda, com oito anos, meu pai resolveu me trazer pra cidade mais próxima que era Floriano do Piauí Princesinha do Sul, e lá eu já tinha tido contato com a escola, mas assim..., foi um contato frustrante, acho que eu tinha seis ou sete anos, o meu pai me levou pra uma escola, era do outro lado do rio, tinha que atravessar a areia quente todos os dias. [...] a professora pra várias turmas multisseriado, ela ainda era merendeira, [...] se preocupava mais com a merenda do que com as aulas, e eu me apaixonei pelo número 2 que ela fazia, minha paixão pela matemática começou a partir daí, [...] a mão dela era muito gordinha e ela desenhava muito o 2 de todos os números apenas o 2 era perfeito. Dona Neném; ela fazia um mingauzinho tão gostoso.

No relato da professora, sua infância não foi diferente de muitas outras crianças daquela época, o que chama a atenção são as dificuldades de ter acesso à escola, uma só professora para várias turmas ao mesmo tempo, também era merendeira, mas, com tantas atribuições, percebe-se o zelo e o cuidado com o ensino da Matemática, possivelmente, a professora mantinha uma relação muito mais próxima com a disciplina, deixando transparecer o gosto pela modelagem matemática.

A professora Tereza contextualiza seu período da infância pontuando as seguintes evidências: 
Eu vivia na cidade com minha mãe, e meu pai vivia na fazenda, meu pai sabia um pouquinho..., mas ele não estava presente, minha mãe, ela cobrava era assim "vai fazer as tarefas menina, vai fazer o dever". [...] então eu tive essa minha dificuldade, hoje é muito cobrado a leitura, então toda vida eu tive muita dificuldade. Acho que foi aonde eu optei pela matemática, mais facilidade.

Segundo a professora, suas dificuldades na infância eram muitas, talvez por não receber apoio, ajuda de maneira nenhuma em relação aos estudos, sua mãe cobrava apenas para cumprir uma obrigação, possivelmente de poder, mas as dificuldades eram tantas perpassando todo seu período da infância.

Considerando o mesmo contexto, a professora Cristina faz seu breve relato dizendo que veio

duma família pobre, eu sou a mais velha de quatorze irmãos, eu não conheço meu pai, só minha mãe, quando minha mãe casou, já tinha eu. [...] não morei muito tempo com minha mãe, até os sete anos morei com minha mãe e meu padrasto, depois fui morar com minha madrinha para estudar, ai fiquei lá até quando casei. Morei no interior, sempre estudei em escola pública, sou de Monte do Carmo, nasci, estudei e morei lá até casar.

O contexto histórico ora relatado com fortes marcas que registra o período da infância da professora Cristina, deixa transparecer as marcas, as dificuldades, a falta de registro de uma família constituída por quatorze irmãos, a falta de apoio familiar que servisse de esteio, de alicerce, uma base sólida que pudesse dar sustentabilidade no entorno e no seio familiar. A falta de conhecimento e de interação na história de vida do seu pai, o pouco convívio e participação ativa com sua mãe, tudo isso provoca um grande questionamento na história de vida da professora.

Em outro momento, quando pedi para a professora Evanete falar um pouco da sua vida enquanto estudante do ensino fundamental, ela faz ressalvas durante alguns momentos da sua vida:

Eu fiz de $5^{a}$ a $8^{\underline{a}}$ série em escola particular, meu pai açougueiro, maior matemático da minha família, tem um raciocínio lógico perfeito, ele é uma calculadora mental fantástica, minha mãe, sempre conselheira. $O$ desafio foi a única filha dele sair e ir estudar a 1000 km, em Campina Grande/PB, fiz vestibular pra matemática sabia que passava e me escrevi para odontologia por que meu pai queria, não passei, então fui fazer matemática, minha família não queria, eles diziam que esse curso era pra homem, nem vai ter formatura, você não vai ter sucesso, foi uma decepção pra minha família, enfim, terminei o curso e ingressei na especialização em matemática. Durante a especialização arrumei um convite pra trabalhar numa Universidade no Tocantins, meus professores conhecendo a minha capacidade eles mesmos mandaram meu currículo.

Mais uma vez é visível o interesse da professora pela matemática, também se percebe a relação familiar pelos cálculos: "meu pai maior matemático da minha família". Tardif (2012), afirmar que o saber dos professores é plural, compósito, heterogêneo, porque envolve no próprio exercício do trabalho, conhecimentos e um saber-fazer bastante diverso, proveniente de fontes variadas e, provavelmente, de natureza diferente. 
A professora Tereza, um pouco tímida, fala desse período de forma rápida enfatizando apenas alguns aspectos desse período:

Assim..., na 2"a $3^{\underline{a}}$ série, sempre a professora..., falava assim..., "vamos fazer uma redação como foi suas férias", depois, o que você vai estudar pra que? "e eu falava que queria ser uma professora de matemática, desde criança mesmo. Então quando surgiu essa oportunidade "deu" trabalhar e foi geralmente pra professor de matemática, era o que tava faltando na escola né, eu acho que foi um presente, que uma coisa assim..., que agente escolhe agente um dia alcança né? Não é que quer dizer que eu lutei, que eu fiz praquilo alí não.

Sua inspiração maior era expressar a vontade em se tornar uma professora de Matemática. O seu relato não deixa transparecer nenhuma relação direta com a disciplina, porém, em seu raciocínio lógico, a matemática era com certeza a possibilidade para um caminho mais fácil e mai próximo para o sucesso da profissão docente. Enquanto a professora Cristina, um pouco mais desinibida, relembra alguns momentos marcantes em sua vida:

Fiz magistério, lá só tinha magistério, naquela época ou fazia magistério ou ficava sem estudar, fiz magistério, em 94 eu comecei a dar aula pra o ensino fundamental I que era de $1^{\underline{a}}$ a $4^{a}$ série. Minha mãe era lavradora, eu não conheci meu pai, minha mãe já faleceu aí eu não..., da história dele, prestei o concurso em 91 e em 94 eu tomei posse, já como professora, ai fiz o vestibular, aquele regime especial, que era só nas férias, então era muito puxado. Mas graças a Deus, se não fosse ele, eu não estaria aqui não viu!

Nesse contexto histórico, o ápice em questão é a coragem, a força de vontade e a determinação de querer vencer na vida, e vencer como profissional da educação, professora de Matemática. Percebe-se que a escolha pela profissão talvez não tenha sido uma decisão própria, e sim, uma oportunidade de momento e de contexto histórico do atual ambiente no qual residia.

Perguntamos a professora Evanete sobre a escolha da profissão e as dificuldades encontradas no ensino e na aprendizagem dos alunos na disciplina de Matemática. Nesse momento a professora volta ao passado e revive uma história de vida e da profissão fazendo algumas reflexões:

Já formada em matemática, fui dar aula de matemática básica no curso de Administração, $1^{\circ}$ dia de aula eu não fui porque eu tinha medo, não sabia o que era dar aula, meus estágios não foram bons, o curso era bacharelado, então eu era cobaia, quando eu cheguei na sala, eles pensavam que eu era uma aluna, cara de menina, nova, recém formada "cara de pobre" aí todo mundo saiu da sala, foi a maior piada, depois se tornaram meus amigos, tive dificuldades na liderança de sala, na didática, mais eu fui aprendendo com eles, na graduação eu só aprendi a calcular, minha prática foi adquirida já atuando, quando fui dar aula no normal superior a professores que dava aula para os menininhos, que tavam lá justamente fugindo da matemática, foi fantástico, ai aprendi com as dificuldades deles, gente..., a educação fundamental é carente. 
"O que aprendi na graduação não era nunca a realidade do que encontrei na sala de aula", eu sabia como aluna, como professora eu não sabia matemática, aprendi ser professora na prática, fui formar professores, eu nem era professora de verdade..., eu sabia matemática, então pra eles aquilo já era importante, imagine..., eu dando aula para professores que já tinha 10 a 15 anos de prática, ai eu lembro que um menino disse assim..., você tem um fôlego, um fôlego, vai ver daqui a três anos, esse fôlego acaba, eu pensei assim..., poxa..., como ele é infeliz na profissão né, ele não se divertia, porque eu sempre me diverti, eu ainda me divirto, eu tive uma ótima formação durante minha prática docente, formar professores da zona rural foi outra realidade.

$N$ nos meus 15 anos de escol, a dificuldade maior é encontrar alunos que queiram aprender. Na $5^{\text {a }}$ série eles gostam do que eu levo para sala, oficinas, jogos, mas, na $8^{a}$ série eles só querem ficar lá fora, meu desafio é apresentar uma matemática fascinante que faça com que eles deixem o mundo lá fora e venham pra dentro, o problema não é só do professor, o aluno tem que querer, depende da família, aulas de reforço, falta incentivo dos pais, é tanto que eu falo assim "vocês aqui do Tocantins não gostam de estudar" e o Brasil inteiro já sebe disso, eu amo o que faço, escolheria a mesma profissão novamente, eu tô realizada, a pior parte é a burocracia, mas dentro de sala de aula, nossa..., eu me divirto realmente.

Percebem-se a frustação da realidade do curso universitário à realidade da sala de aula, imensas lacunas apareceram. Essa realidade não se parecia em nada com a que havia idealizado no curso de licenciatura, assim como também a aprendizagem não era efetiva. Pouco do que lhes era transmitido era realmente assimilado e, menos ainda, compunha-se de coisas significativas. A professora Tereza faz uma retrospectiva da sua profissão:

A minha escolha pela profissão foi decisão própria, a convivência com o professor ali..., a criança toda vida copia muito o professor, fiz graduação na FAFICH em Gurupi, tenho 23 anos de profissão, olha..., eu acho que cada ano que passa mais complicado fica, nos meus primeiros anos de trabalho na matemática, eu acho que eu tinha ajuda do irmão mais velho, em casa, ele orientava e ajudava, agora hoje, eu acho que ta faltando isso aí, então eu acho que a dificuldade vai aumentando. As mudanças são poucas, hoje a sala muda é do concreto, mas não chega até a escola, fica só no discurso, já penso no meu aposentar, eu acho que vai me fazer falta depois, agente se apega aos bichinhos, agente quer fazer o melhor pra eles.

Nesse contexto percebe-se que é imensurável a necessidade de transformação do professor. Se faz necessário um profundo estudo e reflexão sobre a prática do professor, os saberes e a gestão da sala de aula que permita enxergar que a formação, de acordo com Imbernón (2009), deve apoiar-se em uma reflexão dos sujeitos sobre sua prática docente, de modo a lhes permitir examinar suas teorias implícitas, seus esquemas de funcionamento, suas atitudes, realizando um processo constante de auto-avaliação que oriente seu trabalho. Por fim, a professora Cristina conclui sua história, falando sobre sua profissão e suas dificuldades ao longo da sua história de vida: 
Eu comecei a lecionar matemática em 2002, antes de terminar a faculdade, o curso foi uma escolha minha, porque eu gostava de matemática, sempre me identifiquei com matemática, na sala de aula. Eu acho também depende muito do professor, mas tem muito material que agente pode ta trabalhando pra ter uma aula diferente, aqui mesmo na escola, eu também faço, eu confecciono jogos, só que tem um porém, pra trabalhar ta muito difícil, de 2002 pra cá, mudou demais, falta acompanhamento da família, muita indisciplina. [...] De 35 alunos, se você passa um trabalho só 3 ou 4 faz. Aí fica difícil, to tentando superar essas dificuldades e às vezes agente consegue, pelo menos a metade agente consegue, ta ficando muito difícil trabalhar viu! Muitos meninos não gostam mesmo da matemática, já outros falam que gostam; igual chegou uma menina essa semana e disse: "Professora, eu nunca tinha gostado assim..., de matemática, entendido matemática, e com a Senhora estou aprendendo". Deve ser a maneira, uma metodologia diferente das outras professoras. Estou realizada, graça a Deus, apesar das dificuldades encontradas, mas também to contando com a aposentadoria.

As ponderações, indagações, sugestões, sua preocupação com o ensino e a aprendizagem dos alunos é nítida nas expressões utilizadas pela professora. Seu esforço em proporcionar um universo diferente desenvolvendo outras criatividades e relações com os alunos, tem uma explicação para D`Ambrósio (2005) quando ele afirma que

a adoção de uma nova postura educacional, na verdade a busca de um novo paradigma de educação que substitua o já desgastado ensinoaprendizagem, baseada numa relação obsoleta de causa-efeito, é essencial para o desenvolvimento de criatividade desinibida e conducente a novas formas de relações interculturais, proporcionando o espaço adequado para preservar a diversidade e eliminar a desigualdade numa nova organização da sociedade. (p. 82)

\section{Considerações finais}

Esse trabalho foi realizado com o objetivo de ouvir professores que trabalham nos anos finais do ensino fundamental do Colégio Estadual Criança Esperança, sobre sua história de vida enquanto professor de matemática, destacando sua trajetória profissional.

É possível observar, no período da infância das professoras, que a história familiar se repete: suas origens em geral no interior, algumas dificuldades para ter acesso à escola pública ou particular, a escolha pela profissão vinculada à decisão própria, mas mediada pelas relações, desde a infância, com a matemática, o gosto e a facilidade pelo cálculo e pela modelagem como fonte de saber.

É interessante perceber, quando nos remetemos a observar a identidade das professoras, que as dificuldades perpassam por toda história de vida, as lutas, a coragem de vencer, o desafio de enfrentar as situações e sobressair-se vitoriosas daquele contexto. Essas marcas do tempo registram e afirmam o prazer de poder escolher uma profissão, os saberes adquiridos ao longo da trajetória profissional, a conquista e as mudanças de estratégias, o encontro e o reencontro da própria história por outras histórias de vida, de outros professores assemelham-se, e dão sentido a vida e a profissão de ser professor de matemática. 
As tentativas, os erros e os acertos fazem parte do cotidiano da gestão da sala de aula, o conhecimento adiquirido durante a construção do ser e do saber ser, constitui formas diversas de saberes, a reflexão como prática em sala de aula tem promovido o acesso, a permanência e a progressão dos alunos. Tudo isso, tem um sentido universal e contemporâneo: a construção de uma identidade de vida e da profissão docente.

Por fim, D`Ambrósio (2005), afirma que, será impossível entendermos o comportamento da juventude de hoje e, portanto, avaliarmos o estado da educação, sem recorrermos a uma análise do momento cultural que os jovens estão vivendo.

\section{Referências}

D’AMBRÓSIO, Ubiratan. Etnomatemática: elo entre as tradições e a modernidade. Belo Horizonte. Autêntica, 2005.

D`AMBRÓSIO, Ubiratan. A matemática nas escolas. Educação Matemática em Revista, v. 9, n. 11, 2002, p. 44-56.

D’AMBRÓSIO, Ubiratan. Tempo da escola e tempo da sociedade. In: VOLPATO, Raquel Serbino (org.). Formação de professores. São Paulo: Unesp, 1998, p. 1-19.

FERREIRA, Ana Cristina. Um olhar retrospectivo sobre a pesquisa brasileira em formação de professores de matemática. In: FIORENTINI, Dario (org.). Formação de professores de matemática: explorando novos caminhos com outros olhares. Campinas: Mercado de Letras, 2003, p. 19-55.

IMBERNÓN, Francisco. Formação docente e profissional: formar-se para a mudança e a incerteza. São Paulo, Cortez, 2009.

MICOTTI, Maria Cecília de Oliveira. O ensino e as propostas pedagógicas. In: BICUDO, Maria Aparecida Viggiani. Pesquisa em educação Matemática: concepções e perspectivas São Paulo: Unesp, 1999, p. 1-11.

SANCHEZ, Jesús Nicasio Garcia. Dificuldades de Aprendizagem e Intervenção Psicológica. Porto Alegre: Artmed, 2004.

SANTAMARINA, Cristina; MARINAS, José Miguel. Histórias de vida e história oral. In: DELGADO, Juan Manuel; GUTIÉRREZ, Juan Gutiérrez Batman (org.). Métodos y técnicas cualitativas de investigación em ciências sociais. Madrid: Síntesis, 1994, p. 257285.

TARDIF, Maurice. Saberes docentes e formação profissional. Petrópolis: Vozes, 2012.

Severino Roberto de Lima é especialista em Gestão Educacional pela Universidade Federal de Santa Maria, licenciado em Ciências com Habilitação em Matemática pela Faculdade de Formação de Professores de Goiana. Professor efetivo da Secretaria da Educação, Juventude e Esportes do governo do Estado do Tocantins. Endereço: Quadra 902 Sul - Alameda 13 - Lote 07 - 77023-341 - Palmas - TO Brasil.

E-mail: robertolm44@gmail.com.

Recebido em 30 de janeiro de 2018.

Aceito em 12 de abril de 2018. 